1 Ministério da Saúde

(MS) - Brasília (DF), Brasil. Fundação Oswaldo Cruz (Fiocruz), Grupo de Pesquisa Subjetividade, Gestão e Cuidado em Saúde - Rio de Janeiro (RJ), Brasil.

ddscofano@gmail.com

2 Ministério da Saúde (MS) - Brasília (DF), Brasil. Fundação Oswaldo Cruz (Fiocruz), Grupo de Pesquisa Subjetividade, Gestão e Cuidado em Saúde - Rio de Janeiro (RJ), Brasil.

elianeteixeira@globo.com

\section{Navegando por mares nunca dantes navegados: os grupos e seus movimentos}

\author{
Sailing through unexplored seas: groups and their movements
}

Denise Scofano Diniz' $\mathbf{1}^{\text {Eliane dos Santos Teixeira }}{ }^{\mathbf{2}}$

RESUMO Este trabalho pretende traçar um paralelo acerca da dinâmica de grupos constituídos em dois hospitais públicos ao realizarem um curso de Gestão de Emergências, a partir de relatos de experiências das suas respectivas facilitadoras de aprendizagem. Realizaram-se reflexões embasadas na psicossociologia francesa, psicanálise e psicodinâmica do trabalho. Enquanto um grupo viu o curso como meio para expressar o sofrimento pelo não reconhecimento às suas demandas, o outro o percebeu como forma de assumir o protagonismo de suas mudanças. Ambos puderam ter, nesses encontros, a possibilidade de produção de sentidos para suas práticas.

PALAVRAS-CHAVE Pessoal de saúde. Capacitação em serviço. Assistência hospitalar.

ABSTRACT This study intends to draw a parallel about the dynamics of groups constituted in two public hospitals when taking an Emergency Management course, from experience reports of their respective learning facilitators. The authors have conducted reflections from the perspective of French social psychology, psychoanalysis and psychodynamics of work theory. Whereas a group identified this course as a means to express their suffering with the fact that their demands are not recognized, the other realized that this fact would be the chance to take the command of their changes. Both groups were able to have, at those meetings, the opportunity to produce the meanings of their practices.

KEYWORDS Health personnel. Inservice training. Hospital care. 
As armas e os barões assinalados Que da Ocidental praia Lusitana, Por mares nunca dantes navegados Passaram ainda além da Tapiocana, Em perigos e guerras esforçados Mais do que prometia a força humana, $E$ entre gente remota edificaram Novo Reino, que tanto sublimaram.

Luiz de Camões

Os Lusíadas, 1572

\section{Introdução}

O Ministério da Saúde (MS) definiu, por meio da Portaria no 2.395/2011 (BRASIL, 2011), a instituição de colegiado gestor denominado de Núcleo de Acesso e Qualidade Hospitalar (NAQH) como uma das ferramentas para promoção de gestão e cuidado na Rede de Atenção às Urgências e Emergências. Foi proposto, então, um curso de especialização Gestão em Emergências do Sistema Único de Saúde (GES-SUS), ministrado pelo Instituto de Ensino e Pesquisa do Hospital Sírio-Libanês para profissionais e gestores que integravam os NAQHs. O objetivo era propiciar mudanças no cuidado no hospital e reduzir a superlotação das emergências.

O presente ensaio desenvolve uma reflexão teórica sobre o processo de apoio e a dinâmica intersubjetiva e organizacional, a partir das experiências de duas apoiadoras, respectivamente, em dois desses hospitais $\mathrm{H} \alpha$ e $\mathrm{H} \beta$ - contemplados pelo GES-SUS, em um município brasileiro.

Embasadas nos referenciais teóricos de Rene Kaës (2002, 2011, 2012), Eugene Enriquez $(1994,1997)$ e Christophe Dejours $(2001,2012)$ psicanálise, psicossociologia francesa e psicodinâmica do trabalho -, as vivências de ambas as 'apoiadoras-facilitadoras de aprendizagem' foram registradas após as intervenções, e esse material foi recortado e analisado à luz dos seguintes conceitos: o imaginário (ENRIQUEZ, 1997) ante a perspectiva de mudanças na unidade hospitalar; as formações intermediárias (KAËS, 2002) estabelecidas no espaço de realização do curso e a dinâmica de prazer e sofrimento psíquico dos trabalhadores (DEJOURS, 2001) desses hospitais.

Enfatiza-se que movimentos dos grupos do $\mathrm{H} \alpha$ e do $\mathrm{H} \beta$ foram abordados pelas respectivas facilitadoras desses hospitais e que as considerações finais foram abordadas por ambas as autoras.

\section{O GES-SUS}

O processo seletivo do curso de especialização em GES-SUS ocorreu de forma padronizada em todo o País a partir da indicação dos profissionais pela direção da unidade. Concederam-se 20 vagas para cada um dos 22 hospitais públicos com emergência não referenciadas (abertas), selecionados em todo o País. Ocorreu de maio de 2013 a abril de 2014, com carga horária de 360 horas, cujas atividades presenciais foram conduzidas por 'facilitadores de aprendizagem', recrutados entre os apoiadores.

\section{Caracterização do 'Ha'}

O H $\alpha$ é um hospital geral de grande porte, com um serviço de emergência aberta, referência em média e alta complexidade para o Estado. A turma reuniu profissionais com interesses divergentes: os que queriam melhorar o serviço de emergência e os que queriam fechá-lo, expressando expectativas opostas em relação ao curso.

\section{Caracterização do ' $\mathrm{H} \beta$ '}

O H $\beta$ é um hospital geral de médio porte, referência de média e alta complexidade em algumas especialidades, com um serviço de emergência não referenciado no município. Empregaram-se os mesmos critérios já mencionados, para a seleção dos 'alunos' entre os profissionais da unidade. A turma, em geral, parecia ter expectativas positivas quanto ao seu resultado. 


\section{Hospital 'H $\mathbf{\alpha}$ ' - Os movimentos do grupo e o seu imaginário}

O H $\alpha$ passava por uma crise que se assemelhava àquela vivenciada pelos hospitais públicos em 2004-2005 e observada por Sá (2010) quando, em seu estudo, referiu-se aos problemas financeiros, materiais e tecnológicos, corporativismo, a omissão dos profissionais, o clientelismo político etc., cujo saldo é "não apenas a baixa qualidade dos serviços, mas, principalmente sofrimentos, sequelas e mortes evitáveis" (SÁ, 2010, P. 2346).

A iniciativa do GES-SUS representava a possibilidade de propiciar acesso àqueles que perecem nas emergências dos hospitais públicos. Estava posto o desafio de exercer um papel duplo de apoiadora institucional a partir do ideário de "Apoio" (BRASIL, 2010, P. 22) e "facilitadora de aprendizagem".

Ao longo da primeira Unidade Educacional, os alunos faziam avaliações positivas acerca das discussões realizadas. Pareciam se conformar enquanto um grupo com um objetivo comum. O cuidado do paciente e sua trajetória dentro do hospital norteavam as discussões em sala e nas reuniões do NAQH. Era como se os conflitos acerca do destino desse serviço, no hospital, não existissem.

Essa aparente "coesão" do grupo fazia com que se pensasse se estariam sendo estabelecidas alianças "inconscientes", conforme assinala Kaës (2002, P. 24-25). De acordo com esse autor, o "contrato narcisista" do grupo propicia aos seus integrantes sustentarem um discurso comum de ideais e valores, assim como fazerem pactos denegativos para assegurar a continuidade dos investimentos na manutenção da função do ideal e do contrato narcisista (KAES, 2002, P. 25). Assim essa "coesão" acabaria sendo colocada à prova, como poderá ser visto adiante.

Segundo Dejours (2001), o reconhecimento pelo trabalho seria um elemento fundamental na constituição da identidade do sujeito. Era comum os alunos se queixarem de que 'ninguém valorizava o esforço diário para melhorar a assistência' e que esste curso seria uma oportunidade de obter reconhecimento:

Do reconhecimento depende na verdade o sentido do sofrimento. Quando a qualidade do meu trabalho é reconhecida, também meus esforços, minhas angustias, minhas dúvidas, minhas decepções, meus desânimos adquirem sentido. Todo este sofrimento, portanto, não foi em vão; não somente prestou uma contribuição à organização do trabalho, mas também fez de mim, em compensação, um sujeito diferente daquele que eu era antes do reconhecimento. (DEJOURS, 2001, P. 34).

Um dos produtos esperados pelo curso era a elaboração de dois Projetos Aplicativos (PAs) para a implantação de ferramentas de gestão cujos formuladores seriam os próprios autores responsáveis por implantá-los. Diante da insuficiência de espaços instituídos para o diálogo, a hipótese é de que o curso pudesse propiciar um sentido de 'grupalidade', atuando como um espaço de articulação tanto "intrapsíquico" ("compromisso", "eu", metáfora") quanto "interpsíquico" ("mediadores", "delegados", "porta-voz”), e que esses encontros pudessem se tornar espaços favoráveis ao fortalecimento de "processos" e "formações intermediárias" (KAES, 2002, P. 226-227).

A elaboração desses PAs foi uma força motriz para muitos dos alunos por acharem que se conseguiria ter visibilidade no nível central e, consequente, reconhecimento pelo trabalho realizado. Estabeleceu-se, assim, um clima de aparente solidariedade entre os alunos, que impactou em pequenas mudanças dos processos de trabalho. Tornou-se também um potente espaço para reflexões, 'pulsando' ideias e ações, provocando os profissionais a mudarem suas atuações dentro e/ ou em relação à emergência. Mais do que isso, 
movimentou a própria vida dentro da instituição. Conforme assinala Azevedo (2010):

[...] O imaginário motor, ressalta Enriquez, a partir de Winnicott, implica um certo espaço transicional que possibilite a transgressão, o prazer de viver em conjunto, o humor, o prazer estético, a criatividade feliz, todos os fundamentais à atividade reflexiva. $\mathrm{O}$ imaginário motor, instituinte, mostra-se, portanto, como um desafio às regras organizacionais. (AZEVEDO 2010, P. 980).

A segunda Unidade Educacional ocorreu em um cenário político-institucional mais turbulento. A direção do hospital passou a entender que o referido curso era prejudicial ao andamento das atividades da emergência, convocando os alunos para reuniões no mesmo horário das aulas. Os assuntos e propostas abordados em reuniões do NAQH discutidas previamente no curso passaram a ser desqualificados pela direção. $O$ curso permitia 'dar voz' aos profissionais sujeitados a tantas formas de violência institucional no Ha. Além disso, a recusa de uma das autoras, como 'facilitadora de aprendizagem' em atender à exigência da direção de parar o curso, repercutiu negativamente no seu papel de apoiadora e no próprio grupo. Algumas lideranças se evadiram do curso.

As reuniões do NAQH passaram a apresentar mais conflitos. Os profissionais questionavam o curso, a missão do NAQH e a realidade cotidiana da instituição. Sinalizavam a existência de contradições entre o que era estudado e o que era possível executar no $\mathrm{H} \alpha$; o hiato entre o trabalho prescrito pelas diretrizes ministeriais e o trabalho real. "O trabalho é tudo o que, em uma situação real, não foi previsto pela concepção, pelo planejamento e organização de uma tarefa [...]" (DEJOURS, 2012, P. 277).

A terceira Unidade Educacional foi criticada pelos alunos quanto à viabilidade do uso das ferramentas de gestão no $\mathrm{H} \alpha$. Sucederam, então, episódios críticos para a continuidade do NAQH e do curso: o chefe da emergência faltava às reuniões colegiadas; faltavam insumos básicos para a assistência em meio à oferta de alta tecnologia para o curso; mídia e órgãos de controles expunham a superlotação da emergência; além da falta de apoio dos gestores, levaram à desmotivação dos profissionais-alunos. Esses elementos foram usados como justificativa para a ruptura das tarefas acordadas no curso.

Nas quarta e quinta Unidades Educacionais, embora os profissionais se queixassem do curso, ainda era o único espaço de reflexões de suas práticas. Os objetivos dessas Unidades era a conclusão e apresentação dos PAs para o nível central (MS). Alguns se manifestaram contra a apresentação, alegando que os PAs 'exporiam' as falhas dos profissionais e da instituição ao MS. Segundo Kaës (2002), há duas polaridades do pacto denegativo: 'uma organizadora do vínculo' e outra 'defensiva':

[...] o pacto denegativo contribui para esta dupla organização. Ele cria no conjunto do não significável e não transformável: zonas de silêncio, bolsas de intoxicação ou linhas de fuga que mantêm o sujeito estrangeiro à sua própria história. (KAËS, 2002, P. 25-26).

A turma tornou a se mostrar dividida, agora entre os que queriam apresentar os PAs e os que não o queriam. Pareciam achar que, ao apresentar os projetos ao MS, pudessem aniquilar o 'ideal de ego' do grupo sobre as 'suas ilhas de excelências'. Os mesmos grupos que queriam manter a emergência aberta, queriam apresentar (implantar) os PAs e os que desejavam fechar o serviço e não apresentar os PAs.

O grupo se constitui e se desenvolve a partir do momento que alguns desejos inconscientes, exigências de conservação e defensivas consigam ser satisfeitos pela organização. (KAËS, 2012, P. 212-213) 
Era como se a 'demanda' da facilitadora houvesse ativado 'angústia de desintegração, de despedaçamento' que levaram os alunos a verem 'posta em perigo a base que sustentava as alianças inconscientes'. De acordo com Kaës (2002, P. 26-27):

Nas mudanças institucionais, o fantasma de realizar uma instituição diferente, finalmente, conforme à realização das projeções narcisistas, mobilizadora de identificações heroicas pode exercer um grande constrangimento nos sujeitos mobilizados para realizar o projeto e ulteriormente fazer aparecer as dúvidas, as falhas, os sofrimentos ocultados e parcialmente anestesiados.

Apesar dos 'altos' e 'baixos' do grupo, houve baixo absenteísmo das aulas. Atravessaram-se 'mares nunca dantes navegados', começando repletos de esperança quanto às possíveis mudanças que o GES-SUS apontava ao final dessa 'viagem'. Todavia, a perspectiva de falta de resolutividade do espaço do NAQH e a divergência de expectativas dos alunos-profissionais contribuíram para minar os resultados esperados pela coordenação do curso. Azevedo (2010) comenta que o imaginário social/organizacional seria para Enriquez:

[...] certa maneira de representar para nós aquilo que somos, o que queremos ser, o que queremos fazer em que tipo de sociedade e de organização desejamos intervir ou existir. É um sistema de interpretação, de produção de sentido que surge na interação e encontra-se articulado ao desejo dos sujeitos. (AZEVEDo, 2010, P. 980).

Embora, no final da jornada, tenha havido frustração pelo desperdício de recursos investidos nesse hospital, acredita-se que ninguém saiu 'de mãos vazias'. Apesar dos maremotos, o curso propiciou reflexões sobre a gestão e o cuidado. Foram experiências de compartilhamento de estudos e, especialmente, de busca de dar sentido às práticas. Espera-se, então, que se avistem novos mares a serem desbravados.

\section{Hospital Hß}

O H $\beta$ tem como forte característica o envolvimento da equipe gestora, 'capitaneada' pelo diretor geral, comprometido com as orientações do MS, entre elas a formação do NAQH e a elaboração do diagnóstico situacional e plano de ação, onde empregaram ferramentas de gestão de leitos e alguns dispositivos da Política Nacional de Humanização (PNH). Contudo, a rede social do paciente permanecia recebendo pequena consideração, restrita ao curto espaço de uma hora/dia permitido às visitas, as quais precisavam aguardar em longas filas na porta do hospital. Ademais o curso GES tornou-se um momento singular para problematizar esse tema dentro das oficinas de trabalho. A partir da experiência vivenciada por uma das autoras como facilitadora de aprendizagem do curso GES, reflete-se sobre o trabalho em equipe e as funções intermediárias, que afetam e constroem a produção do cuidado na saúde.

\section{As instituições/ organizações}

Ao se analisarem os hospitais enquanto organizações, tem-se em Enriquez (1997) o entendimento de que estes se apresentam como um sistema cultural, simbólico e imaginário. Cultural, pois oferecem uma estrutura de valores e de normas que orientam a conduta de seus membros, definindo papéis a serem cumpridos, em um processo de socialização que reforça os 'bons comportamentos' e exclui os que não os seguem. Tais aspectos são indispensáveis ao estabelecimento e à permanência da organização. No caso do $H \beta$, a cultura gira em torno da missão, voltada 
principalmente ao atendimento ao trauma, com o predomínio de duas 'corporações': a de médicos e de a enfermagem.

Um sistema simbólico, pois as organizações não existem sem elaborar um ou mais mitos unificadores, ritos, heróis - geralmente seus fundadores reais ou imaginários - e 'sagas' que vivem na memória coletiva, orientando os membros da organização em suas ações e comportamentos. Para o $\mathrm{H} \beta$, está presente na ênfase ao papel diante da Rede de Urgências e Emergências como instituição de excelência para o atendimento ao politrauma, gerando sentimento de orgulho nos trabalhadores por pertencerem à 'Família Hß'.

Para Enriquez (1997), o imaginário social/ organizacional se apresenta na organização de duas formas - o motor e o enganador/ enganoso -, sendo insidioso e predominante na vida organizacional; graças a ele, explica Backes (2012), os indivíduos podem viver sentimento de pertencimento, experimentar a admiração ou o temor em relação aos seus chefes, além de poderem sentir o reconhecimento dos demais. Tais conceitos são construções teóricas que ajudam a entender a dinâmica organizacional e não são processos dicotômicos. Ao contrário, toda organização é atravessada, simultaneamente, por processos de criação e repetição.

Dessa forma, o imaginário enganoso estaria presente na força dos 'fantasmas', no 'medo do caos', no ‘temor do desconhecido' e de que a organização fique ameaçada de não 'cumprir da melhor maneira a missão de que é investida'. Já o imaginário motor seria fecundante, pertencendo à categoria do 'diferenciado' e 'porta tríplice sentido': introduz a diferença, ao invés da repetição; é raiz das práticas sociais inovadoras, das utopias - 'o imaginário está ao lado do projeto'. Quando se torna presente, passa a criar rupturas:

Ruptura da linguagem que leva as pessoas a falarem da vida organizacional de outro modo e, portanto, percebê-la sob uma nova face; ruptura nos atos; ele se apresenta como a expressão da espontaneidade criativa da invenção técnica e social; ruptura no tempo: ele é o que permite escapar à cotidianidade, estabelecer um novo ritmo de vida e uma nova dinâmica de trabalho e de relações sociais. (ENRIQUEZ, 1997, P. 36).

Para que uma organização possa constituir uma nova dinâmica de trabalho e ter um projeto em comum, é necessário que seu sistema de valores esteja "suficientemente interiorizado pelo conjunto de seus membros, o que permite dar ao projeto suas características dinâmicas", fazendo-o "passar do estágio de simples plano ao estágio da realização" (ENRIQUEZ, 1994, P. 62). Foi o que se pôde perceber nos grupos formados no curso e que são ótimos exemplos de como esses sistemas se processam.

\section{Análise dos grupos}

A constituição dos alunos em dois grupos foi uma estratégia do curso GES, em que cada um teria como tarefa criar, a partir do levantamento e eleição dos problemas do hospital que desejariam resolver, um projeto de intervenção da realidade - o PA. Considera-se que há uma concordância com a observação de Enriquez de que "um grupo só se constitui em torno de uma ação a realizar, de um projeto ou de uma tarefa a cumprir" (ENRIQUEZ, 1994, P. 61-62).

É importante destacar que o diretor-geral e toda a direção fizeram questão de participar do curso, além de representantes das equipes multidisciplinares dos serviços do hospital. Muitos foram os momentos em que foi possível ao grupo lançar novos olhares sobre a realidade, em que se pôde estimulá-los a novos ângulos e primas. Esse foi o caso da implantação da Visita Aberta dispositivo da $\mathrm{PNH}$-, que aqui será relatado.

Algumas vezes, durante os dois anos em que uma das autoras estava como apoiadora 
institucional do $\mathrm{H} \beta$, houve a sinalização da importância de os pacientes terem sua rede social com acesso ao hospital de forma ampliada, contudo havia forte resistência à proposta. As maiores objeções vinham por parte da enfermagem, que entendia ser um fator que 'atrapalharia' o trabalho com os pacientes, e também dos médicos, que apontavam as dificuldades de terem parentes 'querendo saber sobre os pacientes a toda hora'.

A mudança no olhar foi possível a partir de uma das oficinas de trabalho do curso, cujo tema era a PNH. Ao ressaltar suas dimensões éticas, estéticas e políticas, pôde-se retomar o debate sobre a Visita Aberta, levantando com os especializandos os prós e os contras. Entre os prós: 'melhor interlocução entre usuário/familiar/equipe'; 'diminuição da fila dos visitantes, pois virão em horários diferentes'; 'oportunidade de orientar a família, o que reduziria os agravos e o retorno à emergência'. Já os motivos 'contra': 'atrapalharia os cuidados e a enfermagem se sentiria vigiada'; 'parentes ofereceriam comida para os pacientes antes dos procedimentos cirúrgicos, impedindo-os de realizar na data programada'.

Ao final da listagem, constataram que as vantagens eram bem maiores e/ou tinham maior peso do que os impedimentos, fato que disparou posteriores discussões no NAQH, nos setores do hospital e no Colegiado da Emergência. Dessa forma, nessas reuniões, foram definidos os balizamentos para a Visita Aberta, que foi implantada no mês seguinte à oficina de trabalho.

Durante o mês que se seguiu à implantação desse dispositivo, foram fundamentais para os ajustes do processo as reuniões que fazíamos para discutir as Linhas de Cuidado - Vascular e Ortopedia. Surgiram declarações como 'a visita aberta está trazendo dificuldades porque os visitantes estão pedindo atestado' e 'os parentes e amigos dos pacientes querem falar com os médicos a toda hora'. Isso levava a mais debates em busca de soluções, as quais eram acordadas no final por todos.
Nessa trajetória de mudanças na ordem existente e determinada - por quem e desde quando não se perguntavam nem tampouco importava até iniciarem o processo - no mundo do trabalho, pôde-se ver como se movimentam os imaginários enganoso e o motor. Conforme explica Backes (2012), baseada em Enriquez:

O imaginário enganoso e as significações imaginárias que o constituem, tornam-se a fonte de sentido para as práticas organizacionais e filiação à organização. O imaginário enganoso cumpre para os sujeitos uma função protetora capaz de responder a seus desejos narcísicos de reconhecimento e potência, e, ao mesmo tempo, produzindo um aprisionamento a certo sistema de interpretação da realidade. Já o imaginário motor se expressa como favorecedor da criatividade, da capacidade de questionamento e de autonomia do indivíduo possibilitando contato com mudanças e rupturas. (BACKERS, 2012, P. 50).

O diretor do hospital, confirmando a potência desses movimentos, ao fazer um relato sobre o processo de implantação desse dispositivo em um seminário para a rede de assistência do Estado, refletiu sobre essa dinâmica de transformações no hospital. Afirmou que antes, a Visita Aberta 'não era uma questão para ele e para os gestores'; que o fato de os visitantes ficarem em uma fila, aguardando muitas vezes sob o sol para poderem estar com os pacientes no curto intervalo de uma hora (das $15 \mathrm{~h}$ às $16 \mathrm{~h}$ ), apenas mobilizava ações para mudar o local da fila, e não para que ela deixasse de existir. Disse que 'estava cego' e não via a necessidade nem a possibilidade de implantá-la no hospital, mesmo com as sugestões lançadas pela apoiadora ou pela coordenação do SOS Emergências.

Foi emocionante ouvir esse depoimento, tanto por ter participado desse processo como pela forma singela de sua fala. Uma poesia, 'A função da arte/1', de Eduardo Galeano (2002) me veio nesse momento: 
Diego não conhecia o mar.

O pai, Santiago Kovadloff, levou-o para que descobrisse o mar. Viajaram para o sul.

Ele, o mar, estava do outro lado das dunas altas, esperando.

Quando o menino e o pai enfim alcançaram aquelas alturas de areia, depois de muito caminhar, o mar estava na frente de seus olhos. E foi tanta a imensidão do mar, e tanto seu fulgor, que o menino ficou mudo de beleza.

E quando finalmente conseguiu falar, tremendo, gaguejando, pediu ao pai:

- Me ajuda a olhar!

\section{Funções intermediárias: apoiadora/facilitadora, $o$ líder e o projeto aplicativo}

O duplo papel de facilitadora e apoiadora institucional exercido no $\mathrm{H} \beta$ levou a um crescimento acelerado das atividades e processos. Vivenciou-se em máxima potência o que Campos (2001) sinaliza em seu texto sobre o 'método Paideia', ao esclarecer que aquele que exerce o papel de apoio sustenta e é 'empurrado' pela equipe objeto da intervenção, o que ocorre 'junto e misturado ao mesmo tempo'. Significa, portanto, o 'externo ao grupo', que pode ser proporcionado pelo apoiador/facilitador, cuja função: 'é a tentativa de ampliar a capacidade de as pessoas lidarem com poder, com circulação de afetos e com o saber, ao mesmo tempo em que estão fazendo coisas, trabalhando, cumprindo tarefas'. É 'apoiar o grupo tanto para construir objetos de investimento, quanto para compor compromissos e contratos com outros', sendo fundamental: 'pensar e fazer junto com as pessoas, e não em lugar delas'.

Kaës (2011, P. 23-28) amplia os olhares trazendo outro ângulo em que se pode basear para analisar o papel do apoiador/facilitador e do líder, no caso o diretor do $\mathrm{H} \beta$. O autor entende que o grupo se expressa por meio dos vínculos intersubjetivos que se estabelecem e produzem processos psíquicos, os quais somente são acessíveis a partir do e no grupo. Para o autor, a formação intermediária seria uma categoria para pensar o vínculo entre duas ordens descontínuas da realidade: o dentro e o fora, o consciente e o inconsciente, entre o indivíduo e o grupo.

O líder tem o potencial de exercer uma função de articulação entre os membros do grupo; representar o ideal de ego de cada um dos liderados, que investem, idealizam. Segundo Azevedo et al. (2007, P. 2411),

'[...] os dirigentes ocupam potencialmente uma função estruturante, de intermediação, também de apoio e sustentação nas organizações'. Na função de liderança - que se realiza no contexto intersubjetivo -, 'eles seriam capazes de articular o laço psíquico e social entre os membros do grupo', promovendo possibilidades de mudança, favorecendo 'maior circulação da palavra e autonomia dos sujeitos, na busca de novos sentidos para o trabalho'.

Os dirigentes contribuem ativamente para que possam ser abertas 'brechas no imaginário organizacional dominante', criando o imaginário da mudança, pautada em projeto coletivo, vivido e compartilhado pelos membros da instituição como portador de um sentido. No caso do GES, os PAs dos grupos também exerceram a função de ligação, pois representavam as inquietações e desejos da pluralidade de seus membros. Frisa-se, no entanto, que os PAs foram potentes, desdobrando para ações efetivas no hospital, porque tiveram o apoio do diretor e dos gestores presentes no NAQH, que souberam aproveitar a oportunidade do curso para obterem um planejamento para o hospital. Além disso, o papel exercido pela função de apoiadora/facilitadora a 'costurar' os elos e os fios que se teciam, aparando os conflitos - 'a pluralidade promove conflitos' - e contribuindo para a construção do projeto em comum. Todos esses atores envolvidos no 
curso GES funcionaram como dispositivos de transformação no H $\beta$. Parafraseando Kaës (2011), ressaltaram o singular que traziam para o grupo e que era essencial para a manutenção dele, assim como o plural, que é o que se ganha por pertencer a ele.

\section{Considerações finais}

Embasou-se na tipologia definida por Azevedo (2005) sobre os modelos de gestão dos hospitais de emergência do SUS para pensar os movimentos dos grupos nos dois hospitais. Ela assinala existirem três tipos: a gestão como uma força no sentido de mudança, que pensa como deve ser o hospital, levando a construção coletiva de projeto assistencial ou gerencial; a gestão de problemas cotidianos e desenvolvimento de alguns projetos específicos, não impactando em processo mais amplo de mudança; e a gestão "sob o domínio da urgência" pautado pelo imediatismo, o curto prazo, pelo esforço, o fazer funcionar, "apagando incêndios diariamente" (AZEVEDO, 2005, P. 274-276).

Nessa perspectiva, infere-se que, no $\mathrm{H} \alpha$, predominava o imaginário do 'não reconhecimento', reforçado por uma direção que vivia 'sob o domínio da urgência'. Por isso, as ferramentas de gestão - NAQH, colegiado e o próprio curso - pareciam ser uma 'ameaça', resultando em descontinuidade das ações pelo grupo (no curso e no NAQH). Já no $\mathrm{H} \beta$, cujo imaginário era de 'potência', a gestão participou do curso e o utilizou como oportunidade da elaboração de projeto, apresentação ao MS e promoção de mudanças no hospital. Os participantes do curso constituíram-se como grupo, desenvolvendo outros projetos para o hospital, em seus serviços. Ao terminarem o curso, este buscou executar os PAs (os motes eram: rounds multidisciplinares e a reforma da ambiência da emergência).

Como a organização produz 'dominação, controle e alienação', entende-se ser necessário garantir espaços nos quais as funções intermediárias possam ser exercidas. É importante instituir momentos para reuniões (entre trabalhadores e destes com os usuários) com periodicidade e tempo garantidos na agenda do hospital, assim como promover encontros representados pelos lugares de passagem, de 'dentro/fora', como os cafés e os corredores do hospital, de modo a estimular a organização a produzir outros sentidos: criação, solidariedade, parcerias. Há, também, a necessidade do desenvolvimento de dispositivos que propiciem a produção de autonomia, criatividade e desalienação de forma permanente. Ou, dito de outra forma (MERHY, 1997, P. 84): para que o "trabalho vivo instituinte, que está em ação”, em processo, possa fazer uso do que está dado (instituído) e exerça um certo autogoverno, pensa-se ser imprescindível, no hospital, recriar uma região de experiência (espaço intermediário) onde se possa pensar na prática e transformá-la em práxis reflexiva. Acredita-se que esse percurso de muitos aprendizados permitiu um sentimento como o descrito por Nietzsche (2002, P. 9) sobre momentos especiais pelos quais se passam na vida, quando se conquista

uma renascida fé num amanhã e no depois de amanhã, do repentino sentimento e pressentimento de um futuro, de aventuras próximas, de mares novamente abertos, de metas novamente admitidas, novamente acreditadas.

\section{Agradecimentos}

Os nossos agradecimentos à nossa Mestra Marilene de Castilho Sá pelo convívio, carinho e apoio, tanto por nos incentivar à realização deste projeto quanto por disponibilizar o seu tempo na leitura e troca de ideias visando à melhoria da qualidade deste texto. 


\section{Referências}

AZEVEDO, C. S. Sob o domínio da urgência: o trabalho de diretores de hospitais públicos do Rio de Janeiro. 2005. Tese (Doutorado em Psicologia) - Instituto de Psicologia, Universidade de São Paulo, São Paulo, 2005.

A dimensão imaginária e intersubjetiva das organizações de saúde: implicações para o trabalho gerencial e para a mudança organizacional. Ciência $\mathcal{E}$ Saúde Coletiva, Rio de Janeiro, n. 15, supl, p. 965-974, 2010.

AZEVEDO, C. S. et al. Sob o domínio da urgência: a prática de diretores de hospitais públicos do Rio de Janeiro. Cadernos de Saúde Pública, Rio de Janeiro, v. 23 , n. 10 , p. $2410-2420,2007$.

BACKES, J. C. Os paradoxos do trabalho em equipe em um CTI-pediátrico: entre procedimentos, sofrimentos e o cuidado. 2012. 171 f. Dissertação (Mestrado em Saúde Pública) - Escola Nacional de Saúde Pública, Fundação Oswaldo Cruz, Rio de Janeiro, 2012.

BRASIL. Ministério da Saúde. Política Nacional de Humanização da Atenção. Brasília, DF: Ministério da Saúde, 2010. (Cadernos HumanizaSUS: formação e intervenção, série B: Textos Básicos de Saúde, 1).

Ministério da Saúde. Portaria n ${ }^{\circ} 2.395$, de 11 de outubro de 2011. Organiza o Componente Hospitalar da Rede de Atenção às Urgências no Âmbito do Sistema Único de Saúde. Brasília, DF: Ministério da Saúde, 2011. Disponível em: < http://www.saude. pr.gov.br/arquivos/File/CIBNOVEMBRO7REUNIAO/ componentehospitalardeurgencia.pdf $>$. Acesso em: 28 nov. 2016.

CAMPOS, G. W. S. Paideia e Gestão: um ensaio sobre o Apoio Paideia no trabalho em saúde. 2001. Disponível em: <http://www.gastaowagner.com.br/index. php/2016-05-08-23-30-43/artigos>. Acesso em: $15 \mathrm{dez}$. 2016.

DEJOURS, C. A Banalização da Injustiça Social. 4. ed. Rio de Janeiro: Fundação Getúlio Vargas, 2001.
Trabalho Vivo: sexualidade e trabalho, tomo I. Brasília, DF: Paralelo 15, 2012.

ENRIQUEZ, E. O vínculo grupal. In: MACHADO, Marília N. M. (Org.). Psicossociologia: análise social e intervenção. Petrópolis, RJ: Vozes, 1994. p. 61-74.

A organização em análise. Petrópolis, RJ: Vozes, 1997.

GALEANO, E. O livro dos abraços. 9. ed. Porto Alegre: L\&PM, 2002.

KAËS, R. O grupo e o sujeito do grupo: elementos para uma teoria psicanalítica do grupo. São Paulo: Casa do Psicólogo, 2012

O interesse da psicanálise para considerar a realidade psíquica da instituição. In: CORREA, O. B. R. (Org.). Vínculos e instituições: uma escuta psicanalítica. São Paulo: Escuta, 2002. p. 17-31.

Um singular plural: a psicanálise à prova do grupo. São Paulo: Loyola, 2011.

MERHY, E. E. Em busca do tempo perdido: a micropolítica do trabalho vivo em saúde. In: MERHY, E. E.; ONOCKO-CAMPOS, R. (Org.). Agir em saúde: um desafio para o público. 2. ed. São Paulo: Hucitec, 1997. p. $71-112$.

NIETZSCHE, F. A gaia ciência. São Paulo: Companhia das Letras, 2002.

SÁ, M. C. Subjetividade e gestão: explorando as articulações psicossociais no trabalho gerência e no trabalho em saúde. Ciência e Saúde Coletiva, Rio de Janeiro, v. 5, p. 2345-2354, 2010.

Recebido para publicação em abril de 2016

Versão final em outubro de 2016

Conflito de interesses: inexistente

Suporte financeiro: não houve 